\title{
The Construction Background and Demand Analysis of Logistics Park in H County
}

\author{
Shijun Yuan \\ Hunan Vocational College of Modern Logistics \\ Changsha, China 410131
}

\author{
Jianhua Chen* \\ Hunan Vocational College of Modern Logistics \\ Changsha, China 410131 \\ *Corresponding Author
}

\begin{abstract}
The current logistics industry in $H$ county relatively lags behind, and the construction of its logistics park will actively promote the development of local economy. Based on the analysis on the necessity and feasibility of the construction of the modern logistics park in $H$ County, this paper conducts further analysis and prediction to its logistics demand, obtaining the positioning and main construction contents of the construction of the logistics park.
\end{abstract}

Keywords-commercial logistics; demand analysis; logistics park

\section{INTRODUCTION}

Logistics industry is a composite service industry integrating transportation, warehousing, freight forwarding, information and other industries. It is a basic and strategic industry that supports the development of national economy. To accelerate the development of modern logistics industry is of great significance to promote the adjustment of industrial structure, transform the development mode, raise the national economic competitiveness and build ecological civilization.

\section{THE ANALYSIS ON THE NECESSITY OF THE PROJECT CONSTRUCTION}

\section{A. The Construction of the Project Is Conducive to Promoting the Sustainable Development of H County Regional Economy}

The construction of this project will promote the development of regional logistics industry. The commercial logistics industry has relatively strong impetus effect and correlation degree, rationally allocates regional economic resources, and facilitates enterprises and society to reduce the cost of logistics, finally realizes the enhancement of regional competitiveness and the adjustment of the industrial structure and improves the ability of the regional resources transformation and resources utilization and finds the core of the competitive advantage of regional economy.

\section{B. The Construction of the Project Promotes the Supply-side Reform of the Commercial Logistics in H county}

Through developing the modern commercial circulation of $\mathrm{H}$ county, perfecting the commercial logistics market system of $\mathrm{H}$ county, improving the commercial logistics consumption environment and cultivating market growth points, the construction of this project will drive the commercial logistics consumption in $\mathrm{H}$ county to the direction of intelligence, green, health and safety, and promote the consumption structure upgrading, which is conducive to facilitating the supply-side reform of the commercial logistics in $\mathrm{H}$ county.

\section{The Construction of the Project Is Conducivet to Establishment of the Targeted Poverty Alleviation Platform in the Field of Commercial Logistics}

The construction of this project on the one hand provides a commercial logistics service platform for the innovation and entrepreneurship of farmers, agricultural products enterprises and small and medium-sized commercial logistics enterprises in the peripheral areas of $\mathrm{H}$ county and Hunan, Chongqing and Guizhou, on the other hand provides support services for the industrial poverty alleviation of the developed areas and superior enterprises in this region, which is beneficial to establish a targeted poverty alleviation platform in the field of commercial logistics that radiates to the peripheral areas of $\mathrm{H}$ county and Hunan, Chongqing and Guizhou.

\section{The Construction of the Project Is Beneficial to Promoton of the Intensive Development of the Commercial Logistics in H County}

The construction of the project establishes a commercial logistics platform in the peripheral areas of $\mathrm{H}$ county and Hunan, Chongqing and Guizhou, which will collectively drive the improvement of the organizational and informatization level of the small and medium-sized commercial logistics enterprises in the $\mathrm{H}$ county and Hunan, Chongqing and Guizhou region. It will also be conducive to break down regional and industrial boundaries, and in accordance with the demand scale and growth potential of the commercial logistics, integrate the commercial logistics parks in the peripheral areas of $\mathrm{H}$ county and Hunan, Chongqing and Guizhou which have problems such as insufficient demand and serious homogeneous competition, and drive various scattered commercial logistics, warehousing and distribution resources in this region to link up with the modern commercial logistics park in $\mathrm{H}$ county, so as to improve the service level of the commercial logistics in the surrounding areas of $\mathrm{H}$ county and Hunan, Chongqing and Guizhou. 


\section{E. The Construction of the Project Is Conducive to Establishment of the Urban-Rural Integrated Logistics Network of H County}

The construction of this project will establish a socialized distribution center that radiates to the areas of $\mathrm{H}$ county and Hunan, Chongqing and Guizhou, which will accelerate the settlement of the logistics distribution channels and the establishment of the terminal distribution network notes in the areas of $\mathrm{H}$ county and Hunan, Chongqing and Guizhou, which will be conducive to the establishment of the urban-rural integrated logistics network system that based in this center in the areas of $\mathrm{H}$ county and Hunan, Chongqing and Guizhou, which will serve the needs of the regional urban-rural distribution logistics services.

\section{F. The Construction of the Project Is Conducive to Improvement of the Environment of the Urban Development and Improvement of the Commercial Logistics Industry in H County}

At present, the commercial logistics markets of H County are scattered, small, disorderly and poor, and mainly concentrated along Jianshe Road, so the city traffic pressure is very large. Through the construction of the project, build the modern commercial logistics markets cluster of $\mathrm{H}$ county, improve the quality of $\mathrm{H}$ county commercial logistics industry, and arrange the freight traffic outside the city center as far as possible, which is a very effective measure to relieve the traffic pressure. At the same time, the construction of the project will gather the scattered commercial logistics sites and warehouses into one place, which is conducive to the centralized disposal of the waste products generated in the commercial logistics park, thus conducive to environment protection.

\section{The ANALYSIS ON THE FEASIBILITY OF THE PROJECT CONSTRUCTION}

\section{A. The Steady Improvement of Regional Socio-Economic Strength Creates A Relatively Good Economic Development Environment for the Construction of the Project}

In 2015, the gross regional production of $\mathrm{H}$ County was 5949.29 million yuan, up $0.1 \%$ year on year. From the perspective of different industries: the added value of the primary industry was 649.53 million yuan, up $3.7 \%$ year on year; the added value of the secondary industry was 3275.58 million yuan, down $5.3 \%$ year on year; the added value of the tertiary industry was 2024.19 million yuan, up $10.0 \%$ year on year. The structure proportion of the three major industries in the whole county has been adjusted from 10.2: 59.9: 29.9 in 2014 to 10.9 : 55.1: 34.0 , with continuous optimization of the industrial structure.

\section{B. The Consecutive Years of Releases of the Policies for} Promoting the Development of the Commercial Logistics Industry Provides A Relaxed Policy Environment for the Construction of the Project

In March, 2007, the State Council issued Some Opinions on Promoting the Development of the Service Sector, in March,
2008, the Ministry of Commerce issued Guidance on Accelerating the Development of Modern Logistics in Circulation Area, in March, 2009, the State Council issued the Adjustment and Revitalization Planning of the Logistics Industry, in August, the Opinions of the State Council General Office on the Policy Measures Promoting the Healthy Development of the Logistics Industry (G. B. F. [2001] No. 38) was issued, in 2013, the National Development and Reform Commission issued the Development Plan of the Logistics Parks across the Country (2013-2020), in 2014, the State Council released the Medium and Long-Term Development Planning of the Logistics Industry (2015-2020). In 2016, the first official document issued by the Central Committee of the central government was issued, marking that the "express delivery to the countryside" becomes the national policy; in March, six ministries including the Ministry of Commerce jointly issued the Subject Plan for the Development of ECommerce Logistics in China (2016-2020); in September, the State Council General Office forwarded the Special Action Plan for the Cost Reducing and Efficiency Improving of the Logistics Industry (2016-2018) issued by the National Development and Reform Committee; the General Office of the Ministry of Transport issued Suggestions on Propelling the Acceleration of the Innovative Development of Vehicle-Free Transport Logistics in Pilot Reform; in December, the pure electric logistics vehicles were first listed in the promotion catalogue of the Ministry of Industry and Information Technology. A series of favorable policies are introduced to create a favorable policy environment for the construction of the project.

\section{The Good Development Situation of the Commercial Logistics Industry Provides An Excellent Industrial Development Environment for the Construction of the Project}

In 2016, in the context of the slowing down of the macro economic growth and the changes in the consumer demand structure, the growth of the commercial logistics demand in consumer sector increased steadily, and the commercial logistics structure was further optimized, among them, the ecommerce, express delivery, cold chain, medicine and crossborder e-commerce logistics related to the people's livelihood maintained rapid growth, and the development momentum of the "One Belt And One Road" logistics business related to the national strategy is good.

\section{The Construction Location of the Project Has Superior} Traffic Regional Advantage Which Lays A Solid

Foundation, Which Radiates to the Surrounding Areas, for the Construction of the Project

H County is located at the junction of Hunan, Guizhou and Chongqing provinces, with the No. 209 and No. 319 national highways running through, it is the gateway that connects the Western Hunan with Chongqing and Guizhou, meanwhile, $\mathrm{H}$ county is located at the midpoint of Changsha and Chongqing, it is also the center of the surrounding key cities such as Zhangjiajie, Jishou and Xiushan, which are all about 70 kilometers apart from $\mathrm{H}$ county. In terms of Xiangxi autonomous prefecture, $\mathrm{H}$ County is the hub of the four 
counties (Longshan, Yongshun, Baojing and $\mathrm{H}$ county) of Jishou north district along the No. 209 national highway economic corridor; there are several highways running through $\mathrm{H}$ county, such as Jicha Highway and Zhanghua Highway; in terms of railway transportation, the Xiuzhuang railway from Xiushan in Chongqing to Dizhuang in Hunan and the Jien railway from Jishou in Hunan to Enshi in Hubei meet in $\mathrm{H}$ county; therefore, the location advantage of $\mathrm{H}$ county is second only to that of Jishou in the autonomous prefecture, and the role of its regional transportation hub is obvious.

\section{MARKET FORECASTING}

\section{A. Forecasting of Demand of Home Building Materials}

According to the forecast of urban population size of $\mathrm{H}$ County in Urban Overall Development Plan in $H$ County 2010-2030, the total population size will be 120 thousand in 2020, the middle term, and the total population size will be 160 thousand in 2030, the long term.

At the end of 2015, the population of H County was about 110 thousand. By 2030, based on the newly urbanized population of 3.5 thousand of every year in $\mathrm{H}$ county and per capita housing demand of about 35 square meters, $\mathrm{H}$ county will need an annual increase of new housing area of 125 thousand square meters. If considering the demand for the improving of living standard for housing growth and the demand for commercial housing, new completed area of building should not be less than 150 thousand square meters.

According to the preliminary calculation that per 100 square meters of building consumes about 2 tons of main and auxiliary materials such as board, ceramic tile and oil paint for decoration, the annual demand of logistics for home building materials for decoration is 300 thousand tons.

\section{B. Forecasting of Residents' Daily Consumption Demand}

\section{1) Logistics quantity of daily consumer goods}

TABLE I. PER CAPITA CONSUMPTION OF MAJOR CONSUMER GOODS FROM 2010 TO 2015

\begin{tabular}{|l|l|l|l|l|l|}
\hline & $\begin{array}{r}\text { Year } \\
\mathbf{2 0 1 5}\end{array}$ & $\begin{array}{c}\text { Year } \\
\mathbf{2 0 1 3}\end{array}$ & $\begin{array}{c}\text { Year } \\
\mathbf{2 0 1 2}\end{array}$ & $\begin{array}{c}\text { Year } \\
\mathbf{2 0 1 1}\end{array}$ & $\begin{array}{c}\text { Year } \\
\mathbf{2 0 1 0}\end{array}$ \\
\hline 1. Food and & 79.86 & 106.09 & 105.89 & 130.1 & 127.12 \\
\hline $\begin{array}{l}\text { 2.Vegetable } \\
\text { vegetable products }\end{array}$ & 39.53 & 37.56 & 41.85 & 60.4 & 62.67 \\
\hline 3. Oils and fats & 5.27 & 5.7 & 4.6 & 4.36 & 5 \\
\hline 4. Meat and egg products & 20.79 & 23.32 & 10.85 & 19.57 & 18.91 \\
\hline 5. Aquatic products & 1.73 & 1.91 & 1.49 & 1.4 & 1.31 \\
\hline 6.Drinks \& beverages & 1.86 & 3.31 & 1.69 & 1.97 & 2.28 \\
\hline 7. Sugar & 3.03 & 2.66 & 0.36 & 0.24 & 0.31 \\
\hline 8.Fruit and fruit products & 14.87 & 14.24 & 16.23 & 14.09 & 12.99 \\
\hline Total & 166.94 & 194.79 & 182.96 & 232.13 & 230.59 \\
\hline
\end{tabular}

The average annual per capital consumption of daily goods in H County was 200 kilograms from 2010 to 2015 in "Table I". According to this standard, the annual logistics quantity of the population of 300 thousand in $\mathrm{H}$ County is 60 thousand tons. The annual per capital consumption of fruits and fruit products and meat and egg products is about 30 kilograms, and the logistics quantity of fruits and fruit products and meat and egg products in H County is about 10 thousand tons.

2) Forecasting of logistics quantity of consumer goods in urban households

TABLE II. POSSESSION QUANTITY OF CONSUMER GOODS IN URBAN HOUSEHOLDS IN 2015

\begin{tabular}{|l|l|l|l|}
\hline & $\begin{array}{c}\text { Unit of } \\
\text { measurement }\end{array}$ & \multicolumn{1}{|c|}{ Additional unit } & $\begin{array}{l}\text { Year } \\
\mathbf{2 0 1 5}\end{array}$ \\
\hline Motorcycle & Unit & One hundred households & 19 \\
\hline Moped & Unit & One hundred households & 3 \\
\hline Washing machine & Unit & One hundred households & 97 \\
\hline Refrigerator & Set & & 97 \\
\hline Colour television set & Set & One hundred households & 106 \\
\hline Home computer & Set & One hundred households & 84 \\
\hline Music center & Set & One hundred households & 16 \\
\hline Video camera & Set & One hundred households & 8 \\
\hline Camera & Set & One hundred households & 13 \\
\hline Microwave oven & Unit & One hundred households & 18 \\
\hline Air-conditioner & Unit & One hundred households & 82 \\
\hline Shower water heater & Unit & One hundred households & 97 \\
\hline Fixed-line telephone & Set & One hundred households & 14 \\
\hline Mobile telephone & Set & One hundred households & 321 \\
\hline
\end{tabular}

It is preliminarily predicted that by 2020 the possession quantity of consumer goods in rural households will have reached the level of possession quantity of urban residents in 2015. The logistics quantity of consumer goods is the sum of the logistics quantity of new rural consumer goods and the logistics quantity of the consumer goods' upgrading in urban and rural areas. According to the survey data of "one hundred electric appliances" in $\mathrm{H}$ country, its annual logistics quantity is about 16 thousand tons, If "one hundred electric appliances" account for about $50 \%$ of market shares of $\mathrm{H}$ county, $\mathrm{H}$ county now has about 30 thousand tons of electric appliances (excluding motorcycle, moped and family car) logistics quantity every year as in "Table II".

\section{Forecasting of Demand for Auto Trade and Auto Parts and Auto Repair and Auto Beauty Market}

The population of the whole H County was 312,805 at the end of 2015. By 2020, according to the calculation that per hundred people own 16.1 civilian vehicles averagely on the whole province, the whole county will have 50 thousand civilian vehicles; according to the calculation that the growth rate of civilian vehicles owned by per hundred people is 1.4, per capital will have about an increase of 4300 in H county.

\section{Forecasting of Demand for Agricultural Machinery and Implements Market}

$\mathrm{H}$ County now has an arable area of 368.370 thousand mu, according to the preliminary forecasting that each $30 \mathrm{mu}$ is equipped with a walking tractor by 2020 , a sprayer-duster, a rice transplanter and a grain drying machine, the demand for agricultural implements will be 50 thousand units. Since the implementation of allowance for purchasing agricultural machinery of H County, over the past 9 years, the county has been striving for more than 12.49 million yuan of state agricultural purchase subsidies, has driven farmers to invest 25 million yuan, and has promoted various subsidy machineries of 10.42 thousand units. Therefore, by 2020 , about 40 
thousand agricultural implements need to be added, each year will be about 8 thousand units plus other attached machinery. As a result, the annual total logistics of agricultural implements will be 10 thousand units in the preliminary forecast, if each agricultural implement is calculated at 1,000 $\mathrm{kg}$, the annual logistics quantity will be about 10 thousand tons.

\section{E. Forecasting of Demand for Industrial Logistics Service}

In the main products counted by the industry of the countyscale, sulfuric acid is 127.418 thousand tons, with year-on-year decrease of $29.4 \%$; the electrolytic zinc is about 88.942 thousand tons, with year-on-year decrease of $25.5 \%$; the electrolytic manganese is 91.229 tons, with year-on-year decrease of $31.2 \%$. According to the data statistics of production scale of approved project in industrial park, it can be concluded that the annual scale of finished products in its industrial park is about 1.7 million tons, and if the raw materials and accessories (one ton product needs about 25 tons of zinc sulfide ore during the process of electrolytic zinc, and one product needs about 10 tons of raw ore during the process of electrolytic manganese.) are counted, its annual logistics quantity is at least 20 million tons.

The survey of the logistics of industrial and mining enterprises of $\mathrm{H}$ county shows that the current large-scale industrial and mining enterprises generally rely on the self-run logistics, and there is no willingness to outsource logistics business in recent two years; small and medium-sized industrial and mining enterprises have a certain demand for logistics services, and there is a possibility of logistics outsourcing for the enterprises newly entering the park in the future. Therefore, according to the forecast, the proportion of industrial logistics demand outsourcing will account for $10 \%$ of total logistics demand, that is, 2 million tons.

\section{F. Forecasting of Demand for Agricultural Product Logistics}

Based on the overall development goal of green food industry development planning in Planning of Development and Layout of H county's New Industrialization, by 2020, the cultivated area of green food will reach 320 thousand mu, and the development volume of green food will reach 210 thousand tons.

Therefore, considering the current situation of the production of agricultural products in $\mathrm{H}$ county and the development plan of green food industry, it is preliminarily predicted that the logistics quantity of agricultural products will be 300 thousand tons by 2020 .

\section{G. Brief Summary}

It is preliminarily predicted that by 2020 the logistics quantity of outsourcing of main industrial products, agricultural products and consumer goods in $\mathrm{H}$ county will be:

$\mathrm{H}$ county's outsourcing logistics quantity = home building materials logistics quantity + residents' daily consumer goods logistics quantity + agricultural machinery and farm implements logistics quantity + industrial logistics quantity + agricultural products logistics quantity
$=300$ thousand tons +90 thousand tons +10 thousand tons +2 million tons +300 thousand tons

\section{$=2.7$ million tons}

Since the construction of this project has a strong logistics radiation ability to the surrounding counties and cities, it is preliminarily predicted that the ratio of H county's logistics quantity and the logistics quantity of radiating the surrounding counties and cities is 5:5. By 2020, the total outsourcing logistics quantity in H County will be 5.4 million tons.

\section{CONCLUSION}

Based on the $\mathrm{H}$ county's market demand and urban development planning, the project will be constructed as a regional commercial logistics center, which has the trade circulation operation, logistics operation facilities and integrated environment provided by the trade circulation enterprises, logistics enterprises, industrial enterprises, seeks a foothold in "H county", serves "Hunan, Chongqing and Guizhou" and covers in the mid-south region, and integrates "trade show, warehousing logistics, e-commerce, innovation and entrepreneurship, industry targeted poverty alleviation".

Based on the development plan and market positioning of this project, this project will construct the most influential business logistics infrastructure platform, large e-commerce and logistics information service platform, commercial logistics innovation and entrepreneurship base and modern service industry pilot base in the $\mathrm{H}$ county and border regions of Hunan, Chongqing and Guizhou; the specific contents of the project include integrated office service area, building material and home furnishing, automobile trade and auto parts, auto repair and auto beauty, agricultural machinery and farm implements, cold chain logistics service area, warehousing logistics service area, e-commerce and logistics information service area, modern service industry innovation and entrepreneurship base, supporting services and residential and other management rooms, supporting facilities, etc.

\section{REFERENCES}

[1] Xu Jian, Xia Liangjie and Cao Zhen peng. Prevention and Control of Logistics Park Planning Risk [J]. Logistics Sci-tech. 2009 (03).

[2] Guo Shuqing and Zhu Cuijuan. Scientific Development: The Strategy of Planning and Construction of Logistics Parks in China [J]. Comprehensive Transportation. 2014(10).

[3] Shi Feng. Key Problems of Planning and Design of Logistics Park [J]. Architectural Knowledge 2017(17).

[4] Cao Ming, Luo Lu and Hong Lijing. Problems and Solutions of Logistics Park Planning in China [J]. Journal of Lujiang University. 2009(02).

[5] Fang Dianjun. Logistics Park Planning Method in Germany [J]. China Logistics \& Purchasing. 2005(16). 